\title{
Susceptibility of Soil Bound Mercury to Gaseous Emission As a Function of Source Depth: An Enriched Isotope Tracer Investigation
}

\author{
Maxwell E.E. Mazur, Chris S. Eckley, Carl P.J. Mitchell \\ Version Post-print/Accepted manuscript \\ Citation Mazur, M. E. E.; Eckley, C. S.; Mitchell, C. P. J. Environmental Science \& \\ (published version) Technology 2015, 49 (15), 9143-9149. \\ Publisher's statement This document is the Accepted Manuscript version of a Published \\ Work that appeared in final form in Environmental Science \& Technology, \\ copyright (C) American Chemical Society after peer review and technical \\ editing by the publisher. To access the final edited and published work \\ see DOI: 10.1021/acs.est.5b01747.
}

\section{How to cite TSpace items}

Always cite the published version, so the author(s) will receive recognition through services that track citation counts, e.g. Scopus. If you need to cite the page number of the TSpace version (original manuscript or accepted manuscript) because you cannot access the published version, then cite the TSpace version in addition to the published version using the permanent URI (handle) found on the record page. 


\section{Susceptibility of soil bound mercury to}

2 gaseous emission as a function of source

3 depth: an enriched isotope tracer

4 investigation

5 Maxwell E.E. Mazur ${ }^{\mathrm{a} A}$, Chris S. Eckley ${ }^{\mathrm{b}}$, Carl P.J. Mitchell*a

6

7

8

9 *Corresponding Author: carl.mitchell@utoronto.ca; tel: (416) 208-2744; fax: (416) 287-

$10 \quad 7279$

11 a. University of Toronto Scarborough, Department of Physical and Environmental

12 Sciences, 1265 Military Trail, Toronto, ON, M1C 1A4, Canada

13 b. U.S. Enviornmental Protection Agency, Region 10, 1200 Sixth Avenue, Seattle, WA,

1498101, United States

15 \#. Current address: Alberta Environment and Parks, 111 Twin Atria Building, 4999 - 98

16 Avenue, Edmonton, AB, T6B 2X3, Canada 


\section{Abstract}

18 Soil mercury $(\mathrm{Hg})$ emissions are an important component of the global $\mathrm{Hg}$ cycle.

19 Sunlight induced photo-reduction of oxidized $\mathrm{Hg}$ to gaseous elemental $\mathrm{Hg}$ is an important

20 mechanism controlling emissions from the soil surface, however we currently understand

21 little about how subsurface $\mathrm{Hg}$ stores participate in gaseous $\mathrm{Hg}$ cycling. Our study

22 objective was to investigate the ability of $\mathrm{Hg}$ at deeper soil depths to participate in

23 emissions. Soil fluxes were measured under controlled laboratory conditions utilizing an

24 enriched stable $\mathrm{Hg}$ isotope tracer buried at $0,1,2$ and $5 \mathrm{~cm}$ below the surface. Under dry

25 and low-light conditions, the $\mathrm{Hg}$ isotope tracer buried at the different depths participated

26 similarly in surface emissions (median flux: $7.5 \mathrm{ng} \mathrm{m}^{-2} \mathrm{~h}^{-1}$ ). When the soils were wetted,

$27 \mathrm{Hg}$ isotope tracer emissions increased significantly (up to $285 \mathrm{ng} \mathrm{m}^{-2} \mathrm{~h}^{-1}$ ), with the highest

28 fluxes ( $76 \%$ of emissions) originating from the surface $1-\mathrm{cm}$ amended soils and

29 decreasing with depth. Mercury associated with sandy soil up to $6 \mathrm{~cm}$ below the surface

30 can be emitted, clearly demonstrating that volatilization can occur via processes unrelated

31 to sunlight. These results have important implications for considering how long older,

32 legacy soil $\mathrm{Hg}$ contamination continues to cycle between soil and atmosphere. 


\section{1. INTRODUCTION}

35 The flux of gaseous elemental mercury $(\mathrm{Hg})$ from soils to the atmosphere is an important

36 component of the global mercury cycle, and acts as a control on the accumulation of $\mathrm{Hg}$

37 in soils. ${ }^{1}$ Soil $\mathrm{Hg}$ is typically oxidized (e.g. $\mathrm{Hg}^{2+}$ ) and bound to organic matter with

38 emissions being a function of reduction to $\mathrm{Hg}^{0}$ and its transport and flux from the soil. ${ }^{2}$

39 The magnitude of surface-air fluxes is often significantly correlated with several physical

40 and chemical variables, including: incident solar radiation, soil $\mathrm{Hg}$ concentration,

41 temperature, soil moisture, soil disturbance, soil texture, mineralogy, air $\mathrm{Hg}$ and oxidant

42 concentrations, and atmospheric turbulence. ${ }^{3-7}$

43 Mercury emissions are typically higher during the daytime than at night and are

44 usually strongly correlated with variations in meteorological factors. ${ }^{8}$ Controlled

45 laboratory experiments have confirmed the importance of solar radiation (particularly in

46 the $\mathrm{UV}$ range $410-700 \mathrm{~nm}$ ) in promoting the photo-reduction of $\mathrm{Hg}^{2+}$ to $\mathrm{Hg}^{0}$ and

47 subsequent emission. ${ }^{79-11}$, During night/dark conditions, some studies have shown that

48 Hg emissions cease or change direction toward net deposition. ${ }^{4,8}$ While nighttime fluxes

49 are usually lower than daytime, significant $\mathrm{Hg}$ emissions can occur during dark/low-light

50 conditions and be an important contributor to the overall magnitude of diel emissions. ${ }^{9}$

51 Mercury fluxes from forested soils during the growing season mostly occur during low-

52 light conditions because closed canopies provide significant shading and very limited

53 solar radiation reaches the surface. ${ }^{12}$

54 Given that solar radiation cannot penetrate beyond the surface, possibly only the

55 very top of the soil column can supply $\mathrm{Hg}$ for emission via photo-reduction. ${ }^{10,13,14}$ To 
56 sustain emissions over time for radiation-driven fluxes, the surface layer must be

57 replenished from above (e.g. wet/dry deposition) and/or below the soil interface. The

58 potential for sub-surface transport and subsequent emission is not well understood, but

59 has important implications for the mobility of the large pool of terrestrial $\mathrm{Hg}$ that occurs

60 below fresh/partially decomposed litter. ${ }^{15}$ Recent studies have suggested that sub-surface

$61 \mathrm{Hg}$ transport contributes to surface emissions; however there remain important questions

62 regarding the depth over which these processes operate and the variables controlling their

63 release..$^{16,17}$

64 In field and laboratory studies, soil $\mathrm{Hg}$ emissions often increase in response to

65 rain events/surface wetting. ${ }^{6,18-20}$ Possible mechanisms for this phenomenon include

66 physical displacement of $\mathrm{Hg}$ in interstitial soil air, $\mathrm{Hg}$ release from soil due to

67 competition for binding sites by polar water molecules, and preferential photo-reduction

68 of soluble pore water $\mathrm{Hg}^{2+}$ to $\mathrm{Hg}^{0} \cdot{ }^{20-23}$ Mercury dissolved in soil water may also be

69 transported vertically toward the surface via capillary forces, particularly as the soils

70 dry. $7,17,19,20$ The extent over which vertical $\mathrm{Hg}$ transport may occur and then participate in

71 soil $\mathrm{Hg}$ fluxes could be better elucidated through tracer experiments, but no such research

72 has yet been undertaken.

73 In this study, we used an enriched stable $\mathrm{Hg}$ isotope tracer in laboratory

74 experiments to identify the susceptibility of soil $\mathrm{Hg}$ to emission in relation to the depth of

75 the Hg source in the soil column. This objective was investigated under both dry and wet

76 soil conditions. Understanding the extent to which soil $\mathrm{Hg}$ at different depths is able to

77 participate in surface emissions and continue to actively cycle environmentally, versus

78 being strongly sequestered by soil burial, is important for predicting ecosystem response 
79 times to changes in anthropogenic $\mathrm{Hg}$ emissions. Our use of an enriched stable isotope

$80 \mathrm{Hg}$ tracer provides a powerful tool that allows the direct observation of $\mathrm{Hg}$ flux dynamics

81 originating from specific soil depths. Such direct measurements are important in

82 supporting/rejecting existing theories regarding surface $\mathrm{Hg}$ emissions based on field and

83 laboratory observations of ambient $\mathrm{Hg}$. We hypothesized that deeper soil layers

84 contribute to $\mathrm{Hg}$ emissions and that episodes of soil wetting promote subsurface $\mathrm{Hg}$

85 transport and increase the potential for $\mathrm{Hg}$ in deeper layers to be released via surface

86 emission.

88 2. EXPERIMENTAL

\subsection{Experimental design}

90 Controlled laboratory experiments to measure gaseous $\mathrm{Hg}$ fluxes from soil were

91 conducted, mimicking conditions observed at the forest floor during summer leaf-out in a

92 deciduous forest, similar to the setting in recent field research. ${ }^{24}$ This included constant

93 low-light $\left(18 \pm 5 \mathrm{~W} \mathrm{~m}^{-2}\right)$ irradiance supplied by two fluorescent tubes with relatively

94 stable air $\left(24 \pm 1^{\circ} \mathrm{C}\right)$ and soil temperatures $\left(22 \pm 2^{\circ} \mathrm{C}\right)$. The low-light conditions contrast

95 with other experimental work intended to mimic a desert setting (e.g., Ericksen et al. ${ }^{25}$ ),

96 but are representative of the $\sim 20 \mathrm{~W} \mathrm{~m}^{-2}$ average irradiance observed during the breadth of

97 overcast to full-sun conditions at the deciduous forest floor during summer. ${ }^{12}$

98 In each experiment, we laid 1-cm deep layers of sandy soil labeled with an

99 enriched stable $\mathrm{Hg}$ isotope tracer $\left(91.09 \%\right.$ abundance ${ }^{199} \mathrm{Hg}$ amended as $\left.\mathrm{HgCl}_{2}\right)$ at 
100 different depths (surface, $-1 \mathrm{~cm},-2 \mathrm{~cm}$, and $-5 \mathrm{~cm}$, plus a control without a tracer-

101 amended soil layer) in experimental mesocosms, and measured gaseous $\mathrm{Hg}$ fluxes to the

102 atmosphere using dynamic flux chambers and gold traps (measurements detailed in

103 section 2.1.2). Experimental mesocosms consisted of a polycarbonate container (length

$10442 \mathrm{~cm}$, width $33 \mathrm{~cm}$, height $17 \mathrm{~cm}$ ) with a perforated bottom to allow drainage during

105 wetting of the soil (Figure 1). Experiments were conducted in random order, one replicate

106 at a time using $10 \%$ nitric acid washed mesocosm containers. Apart from the depth at

107 which the labeled soil was laid down, each experiment was conducted exactly the same

108 with respect to soil handling and timing. Soil was left to sit in tubs for one week prior to

109 being used in each experimental replicate. Each of the five different experimental

110 treatments (labeled soil at surface, $-1 \mathrm{~cm},-2 \mathrm{~cm},-5 \mathrm{~cm}$ and an unlabeled control) was

111 conducted in triplicate for a total of 15 separate, multi-day experiments. For each

112 experiment, unamended soil (without the $\mathrm{Hg}$ tracer) was carefully added into the

113 container, the depth depending on the experimental treatment. Soil amended with ${ }^{199} \mathrm{Hg}$

114 tracer was then carefully placed as a 1-cm deep layer at the experimental depth, defined

115 as the top of the amended soil layer. Except for experiments with amended soil at the

116 surface, unamended soil was then added to ensure each experiment had a total soil depth

117 of $8 \mathrm{~cm}$. 


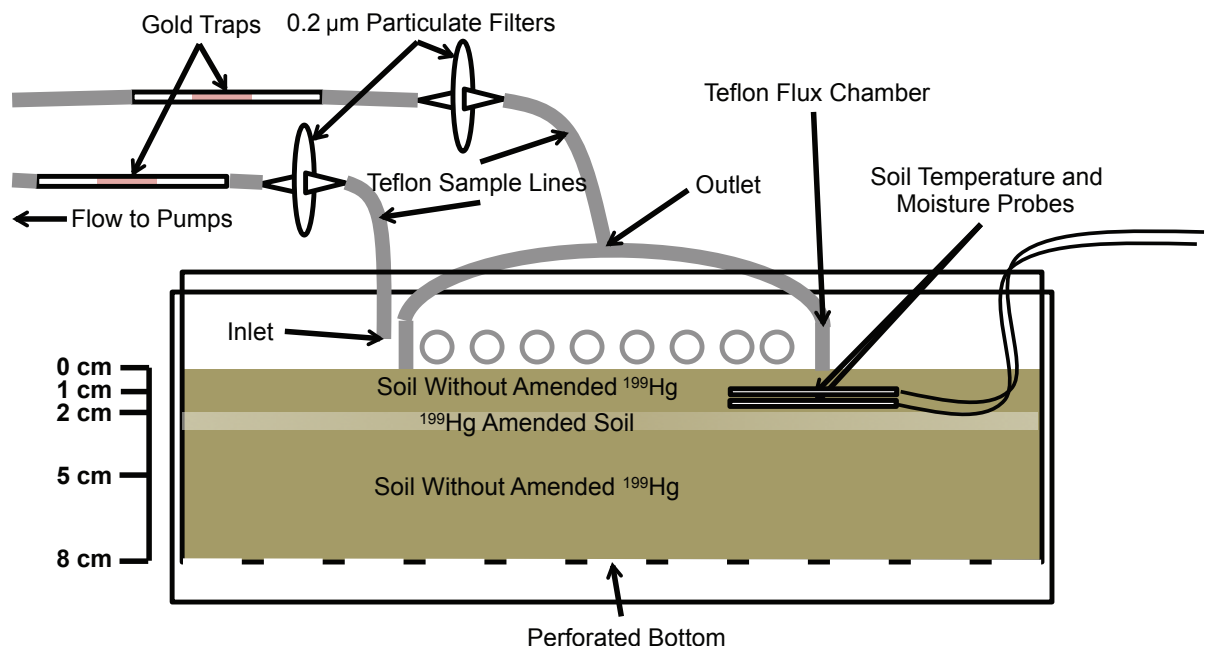

119 Figure 1: Diagram of the experimental apparatus. This example is for an experiment with $120{ }^{199} \mathrm{Hg}$ amended soil at 2-cm depth.

121 In each experiment, a series of $\mathrm{Hg}$ flux measurements were conducted over a

122 period of approximately one day on each mesocosm when soils were dry $(n=3-4$ for each

123 experimental replicate). Soils were then wetted to approximate field capacity by slowly

124 adding deionized water until droplets of water formed along the perforations on the

125 bottom of the soil mesocosm. Water was added over a perforated lid secured to the top of 126 the mesocosm container to simulate rainfall, although our rate of addition (a total of 2.51 ;

127 equivalent to $180 \mathrm{~mm} \mathrm{hr}^{-1}$ ) was much higher than usually observed. A piece of nytex

128 mesh was placed directly onto the surface of the soil to reduce the velocity of water

129 droplets and to better disperse droplets such that wetting was even and imparted as little

130 physical disturbance to the soil surface as possible. ${ }^{28}$ Following soil wetting, mercury

131 flux measurements ( $\mathrm{n}=9-12$ for each experimental replicate) continued for approximately 1323 days. 
135 To ensure consistency, soil was prepared in large batches in the lab by combining sand

136 with high organic content soil, to a final organic matter content of $5 \pm 1 \%$ by mass. A

137 sandy soil with organic matter content of $\sim 5 \%$ was chosen as it is representative of

138 surface upland forest soils in the western Great Lakes region of North America. ${ }^{24,26}$

139 When packed in the experimental mesocosms, mean bulk density of the soil was $1.14 \mathrm{~g}$

$140 \mathrm{~cm}^{-3}$, which is similar to unimpacted sandy loam surface soils (mean of $1.05 \mathrm{~g} \mathrm{~cm}^{-3}$ in

141 Stone and Eliof $\mathrm{f}^{29}$ ) within the northern Minnesota region on which this lab study was

142 based. Field capacity was estimated from the continuous soil moisture data measured in

143 the experiments (i.e., where soil moisture content begins to stabilize post-wetting) as 0.28

$144 \pm 0.03$ (mean \pm standard deviation)

145 Ambient $\mathrm{Hg}$ concentrations in the soils were very low, ranging from 0.6-4.2 ng

$146 \mathrm{Hg} \mathrm{g}^{-1}$ dry weight, with a median concentration of $1.4 \mathrm{ng} \mathrm{Hg} \mathrm{g}^{-1}$. Isotope amended soil

147 layers were created by mixing dry soil with an enriched ${ }^{199} \mathrm{Hg}$ tracer solution (made from

148 a stock batch of enriched, $91.09 \%$ abundance ${ }^{199} \mathrm{HgCl}_{2}$ ) to a target final soil concentration

149 of $100 \mathrm{ng}{ }^{199} \mathrm{Hg} \mathrm{g}^{-1}$. This concentration is representative of background soil

150 concentrations where point sources of $\mathrm{Hg}$ pollution do not exist. ${ }^{27}$ Each amended soil

151 batch was allowed to air-dry completely (1-2 days) before incorporation into each

152 mesocosm. Soil then settled in mesocosms for 7 days before starting experiments,

153 effectively allowing for complete incorporation of the added isotope tracer into the solid

154 soil matrix. 


\subsubsection{Measurement details}

157 Gaseous Hg emissions were measured using a cylindrical Teflon dynamic flux chamber

$158\left(0.036 \mathrm{~m}^{2}\right.$ footprint, $6.5 \mathrm{~cm}$ height, 2.0 litre volume, with $1 \mathrm{~cm}$ diameter inlet holes every

$1592.5 \mathrm{~cm}$ around the perimeter and a $5 \mathrm{~cm}$ wide bottom flange $)^{5}$ placed directly on the

160 surface of the soil mesocosms. Gold traps, utilizing gold-coated silica beads, were used to

161 accumulate $\mathrm{Hg}$ in air. We simultaneously sampled air from two locations using two

162 different gold traps: immediately adjacent to one of the flux chamber's perforated side

163 inlets (using a retort stand to hold the inlet line in place) and from the outlet port at the

164 top of the flux chamber (Figure 1)..$^{13}$ Air sampling pumps were utilized to draw air

165 through the gold traps at a rate of $1.51 \mathrm{~min}^{-1}$. A bubble flow calibrator was used to verify

166 this flow rate before and after every measurement. The Hg flux was calculated as:

$167 \quad \mathrm{~F}=\mathrm{Q} *\left(\mathrm{C}_{0}-\mathrm{C}_{\mathrm{i}}\right) / \mathrm{A}$

168 where $\mathrm{F}$ is the $\mathrm{Hg}$ flux $\left(\mathrm{ng} \mathrm{m}^{-2} \mathrm{~h}^{-1}\right), \mathrm{Q}$ is the chamber flushing flow rate $\left(\mathrm{m}^{3} \mathrm{~h}^{-1}\right), \mathrm{C}_{0}$ is the

169 air $\mathrm{Hg}$ concentration measured at the outlet $\left(\mathrm{ng} \mathrm{m}^{-3}\right), \mathrm{C}_{\mathrm{i}}$ is the $\mathrm{Hg}$ concentration measured

170 at the inlet, representing the amount of $\mathrm{Hg}$ flowing into the chamber's inlet holes, and $\mathrm{A}$

171 is the footprint area of the chamber $\left(\mathrm{m}^{2}\right)$.

172 Measurement durations ranged from 30-120 minutes; shorter durations were used

173 to rapidly collect several flux measurements under stable conditions (i.e. blanks, dry

174 fluxes) while longer durations were used to characterize flux response to wetting.

175 Chamber blank measurements were made prior to each experiment to verify the

176 cleanliness of the flux chamber (the flux chamber was soaked in $10 \%$ nitric acid and 
177 rinsed thoroughly following each experiment). Chamber blank measurements were made

178 over clean polycarbonate film laid on top of the experimental soil. Similar to other

179 studies, chamber blank fluxes were low $\left(0.6 \pm 1.2 \mathrm{ng}^{199} \mathrm{Hg} \mathrm{m}^{-2} \mathrm{~h}^{-1}\right)$ indicating no influence

180 on the observed fluxes due to the chamber itself. ${ }^{5,13}$ Physical environmental variables,

181 including air temperature (Campbell Scientific CR1000 internal temperature sensor), soil

182 temperature (BetaTherm 100K6A1B thermistor), soil moisture content (Decagon Devices

183 EC-5 soil moisture sensor) at 1-cm depth, and incident solar radiation (Kipp \& Zonen SP-

184 LITE2 Silicon Pyranometer) were logged at 1 minute intervals using a Campbell

185 Scientific CR1000 data logger throughout each experiment.

\subsection{Analytical methods}

188 Desorption of gaseous $\mathrm{Hg}$ adsorbed to the gold traps was carried out on a Tekran 2600

189 mercury analyzer, using the US EPA Compendium Method IO-5 for sampling vapour

190 phase $\mathrm{Hg}$ in ambient air. ${ }^{30}$ Mercury isotopes were detected by directly hyphenating the

191 Tekran desorption system to an Inductively Coupled Plasma Mass Spectrometer (ICP-

192 MS; Agilent Model 7700x). In brief, the sample gold trap was thermally desorbed in a

193 stream of $\mathrm{Hg}$-free argon and collected onto a second pure gold trap. The second trap was

194 thermally desorbed and introduced directly into the torch of the ICP-MS, which was

195 programmed to detect $\mathrm{Hg}$ isotopes, specifically ${ }^{199} \mathrm{Hg}$ (the dominant isotope in the $\mathrm{Hg}$

196 tracer) and ${ }^{202} \mathrm{Hg}$ (the most naturally abundant $\mathrm{Hg}$ isotope). We used a 5-point calibration

197 curve $\left(r^{2}>0.99\right)$ before each analysis using manual injections of known quantities of

198 gaseous $\mathrm{Hg}$ dispensed from a Tekran 2505 calibration unit. Periodically during analysis 
199 (every 10 samples) ICP-MS detector stability was verified and drift was monitored with 200 manually injected $\mathrm{Hg}$ samples. Gold traps were tested after each use to ensure desorption 201 efficiency using manual injections of known quantities of $\mathrm{Hg}$ and were removed from use 202 if the desorbed $\mathrm{Hg}$ quantity differed by $>10 \%$. The mass of $\mathrm{Hg}$ desorbed from each trap 203 that was attributed to excess ${ }^{199} \mathrm{Hg}$ mercury isotope content (henceforth: tracer $\mathrm{Hg}$ ) as

204 well as the ambient $\mathrm{Hg}$ naturally present (measured using the most naturally abundant 205 stable isotope, ${ }^{202} \mathrm{Hg}$; henceforth: ambient $\mathrm{Hg}$ ) was calculated using the matrix 206 calculations described in Hintelmann and Evans ${ }^{31}$, which take into account the certified 207 isotope abundances of the ${ }^{199} \mathrm{Hg}$ tracer and natural $\mathrm{Hg}$ isotope abundances. The detection 208 limit for ${ }^{199} \mathrm{Hg}$ fluxes was $3.4 \mathrm{ng} \mathrm{m}^{-2} \mathrm{~h}^{-1}$. Analytical precision, calculated as the relative 209 standard deviation of ${ }^{199} \mathrm{Hg} /{ }^{202} \mathrm{Hg}$ ratios from known, natural abundance $\mathrm{Hg}^{0}$ injections 210 was $1.6 \%$.

211 At the end of each experiment the soil mesocosm was carefully sectioned into 212 samples of $1-\mathrm{cm}$ thickness ( $10 \mathrm{~g}$ each). These samples were analysed simultaneously 213 both for excess tracer $\mathrm{Hg}$ concentration and ambient $\mathrm{Hg}$ concentration. Each sample was 214 digested according to US EPA Method 3051A using concentrated nitric acid in a

215 microwave digester. ${ }^{32}$ The digestate was diluted with deionized water, oxidized by

216 adding $1 \%$ by volume $\mathrm{BrCl}$, and analysed using a Tekran 2600 automated mercury

217 system, for desorption via US EPA method $1631,{ }^{33}$ directly hyphenated to our ICP-MS.

218 Briefly, this system automatically mixes $\mathrm{SnCl}_{2}$ with each sample digestate to reduce the $219 \mathrm{Hg}^{2+}$ in the sample to $\mathrm{Hg}^{0}$, which is stripped from the aqueous mixture by passing $\mathrm{Hg}$-free 220 argon across a glass rod phase separator, and then dual amalgamating the vapour onto 221 gold traps. The gold traps are thermally desorbed in succession and the $\mathrm{Hg}$ vapour is 
222 passed directly into the ICP-MS for detection of the specific Hg isotopes. Our QA/QC

223 procedures included random inclusion of blanks, duplicates, spikes, and certified

224 reference materials (MESS-3). The detection limit for soils, calculated as three standard

225 deviations of digestion blanks was $0.03 \mathrm{ng}^{199} \mathrm{Hg} \mathrm{g}^{-1}$. Duplicate relative standard

226 deviations were on average $4.3 \%$ for ${ }^{199} \mathrm{Hg}$, spike (ambient) recoveries were $96 \pm 3 \%$, and

227 the recovery of standard reference material was $95 \pm 4 \%$.

$229 \quad$ 2.3. Statistical methods

230 Where analyzed samples from the gold traps and soil sections (for ambient and tracer $\mathrm{Hg}$ )

231 were below the practical detection limit of the analysis methodology, a value of zero was

232 assigned. Statistical tests were carried out using the RStudio package. ${ }^{34}$ Non-parametric

233 statistical methods were used throughout the paper because the data were not normally

234 distributed (Shapiro-Wilk test, $\mathrm{p}<0.05$ ). The Wilcoxon-Mann-Whitney test was utilized

$235(\alpha=0.05)$ to make comparisons between wet and dry fluxes measured from each tracer-

236 depth experiment. Correlations among measured variables were analyzed using

237 Spearman's rank order correlation coefficient $(\alpha=0.05)$.

239 3. RESULTS AND DISCUSSION

$240 \quad$ 3.1. Mercury fluxes from subsurface sources under dry, $241 \quad$ low light conditions 
242 The ambient $\mathrm{Hg}$ fluxes were similar and relatively low throughout the experiments

243 (median ambient flux: $0.2 \mathrm{ng} \mathrm{m}^{-2} \mathrm{~h}^{-1}$, range: -9.5 to $+19.1 \mathrm{ng} \mathrm{m}^{-2} \mathrm{~h}^{-1}, \mathrm{n}=36, \mathrm{p}=0.21$ ),

244 likely as a result of the low ambient $\mathrm{Hg}$ concentrations in the soils and indicating that the

245 conditions promoting $\mathrm{Hg}$ fluxes were consistent between experimental treatments (Figure

246 2A). The results of the tracer $\mathrm{Hg}$ depth experiments showed that the emission of tracer

$247 \mathrm{Hg}$ under dry, low-light conditions was similar regardless of tracer depth (median tracer

248 flux from all depths: $7.5 \mathrm{ng} \mathrm{Hg}^{199} \mathrm{~m}^{-2} \mathrm{~h}^{-1}$, range: 0 to $68 \mathrm{ng} \mathrm{Hg}^{199} \mathrm{~m}^{-2} \mathrm{~h}^{-1}, \mathrm{n}=36, \mathrm{p}=0.19$,

249 Figure $2 \mathrm{~B}$ ). These tracer $\mathrm{Hg}$ fluxes were significantly greater than observed in control

250 experiments where ${ }^{199} \mathrm{Hg}$ was not added $(\mathrm{p}<0.0001)$. As such, our results clearly indicate

251 the ability for subsurface $\mathrm{Hg}$ pools to participate in surface emissions, even in the

252 absence of significant soil moisture. In addition, this demonstrates the potential for

253 surface $\mathrm{Hg}$ emissions to occur under low-light conditions presumably through processes

254 other than photo-reduction. As indicated by other studies, we expect that emissions from

255 the surface amended soil layer would have been much larger than subsurface emissions if 256 our mesocosms were exposed to higher levels of solar radiation. ${ }^{13,19,35,36}$

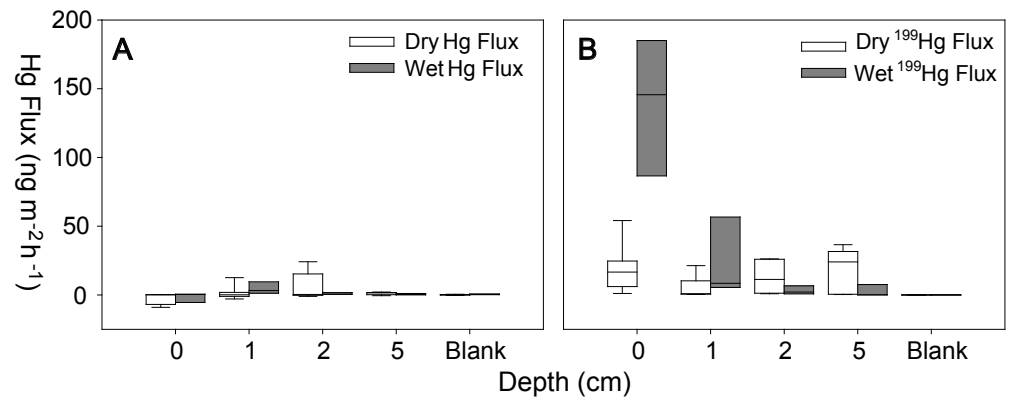

258 Figure 2: Box plots of: A) ambient $\mathrm{Hg}$ fluxes, B) tracer $\mathrm{Hg}$ fluxes in relation to depth of

259 the enriched stable $\mathrm{Hg}$ isotope tracer amended 1-cm soil layer. Boxes correspond to range 260 between $25^{\text {th }}$ and $75^{\text {th }}$ percentiles, with medians marked. Where data available, $5^{\text {th }}$ and 
$26195^{\text {th }}$ percentiles represented by whiskers. The ambient $\mathrm{Hg}$ fluxes were measured at the

262 same time as the tracer $\mathrm{Hg}$ fluxes; however the soil depth where the ambient flux

263 originated should not be inferred from the data. Instead, the ambient data represents the

264 variability in flux measurements that occurred throughout the experiment that is un-

265 related to the tracer $\mathrm{Hg}$ addition to the soil. Overall, the ambient data showed that

266 conditions were relatively stable throughout the experiment.

267 Since we maintained low-light conditions throughout our study, and observed $\mathrm{Hg}$ 268 emissions from sources at depths much greater than light penetration (up to $5 \mathrm{~cm}$ below 269 the surface), it is likely that a non-light related mechanism was occurring. These results 270 differ from Quinones and Carpi $(2011)^{16}$ which focused on much shallower soil depths 271 and higher light conditions and concluded the light may continue to drive emissions to a 272 depth of $0.4 \mathrm{~cm}$ below the surface. While the exact oxidation state of the amended $\mathrm{Hg}$ 273 tracer was not tracked in our mesocosms, similar experiments using $\mathrm{Hg}^{2+}$ amended soils

274 indicate that amended $\mathrm{Hg}$ tracers are entirely bound to soil particles as $\mathrm{Hg}^{2+}$ with no 275 detectable fraction of $\mathrm{Hg}^{0} .{ }^{37}$ Therefore in order to observe emission of $\mathrm{Hg}$ from our 276 experimental mesocosms, reduction of $\mathrm{Hg}^{2+}$ to $\mathrm{Hg}^{0}$ had to occur in dark and low-light 277 conditions. Other studies that observed $\mathrm{Hg}$ emissions in the absence of radiative sources 278 identified elevated soil temperature as a significant correlate, however the exact 279 mechanisms remains poorly substantiated due to the relatively low magnitude of 280 observed emissions. ${ }^{9,13,14,36,38}$ Both Xin et al. ${ }^{14}$ and Kim et al. ${ }^{36}$ identified temperature as 281 an important variable associated with the release of soil bound $\mathrm{Hg}^{0}$, exhibiting 282 sufficiently low activation energy to occur at environmental soil temperatures, however 283 reduction would still need to occur for the creation of soil bound $\mathrm{Hg}^{0}$. In light of findings 
284 from other studies, we propose two probable mechanisms resulting in the emission of $\mathrm{Hg}$

285 from soils not exposed to light. The bulk of associative evidence linking soil temperature

286 to $\mathrm{Hg}$ emissions in dark conditions suggests a mechanistic link, potentially as a form of

287 thermal reduction whereby elevated soil temperatures provide substantial energy to

288 reduce soil bound $\mathrm{Hg}^{2+}$ to $\mathrm{Hg}^{0}$. Alternatively, though most likely in tandem with a thermal

289 mechanism, chemical reduction of $\mathrm{Hg}^{2+}$ via abiotic reactions with humic matter or other

290 chemical reductants may also contribute to the $\mathrm{Hg}$ emissions observed under dark

291 conditions. ${ }^{39}$ Biotic reduction $^{40}$ is another possibility that can potentially have significant

292 impacts on $\mathrm{Hg}$ reduction in this system and more likely real world systems, but

293 investigating the impact of this specific factor is outside the scope of this study. Our

294 experimental design involving the amendment of soil with $\mathrm{Hg}^{2+}$ allowed us to identify

295 that a reduction process occurs in the absence of light and can produce a constant source

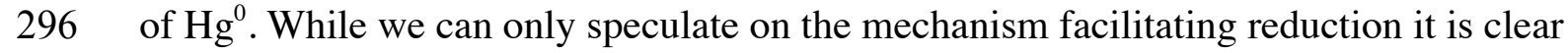

297 that under dry, low light conditions $\mathrm{Hg}$ fluxes can originate from sources at least as deep

298 as $5 \mathrm{~cm}$ at significant, albeit relatively low magnitudes.

\section{$300 \quad$ 3.2. Mercury fluxes following wetting of dry soil}

301 In our wet soil experiments, fluxes of ambient $\mathrm{Hg}$ following wetting showed no distinct

302 trends associated with the depth of tracer $\mathrm{Hg}$ amended soil ( $\mathrm{p}=0.141$, Figure 2A). Tracer

$303 \mathrm{Hg}$ fluxes were similar across experiments prior to wetting, but fluxes increased

304 substantially when soils were wetted to field capacity, with the largest fluxes observed

305 post-wetting, when soils began to dry (Figure 2B, 3). Peak shape and timing agree well 
306 with observations from other studies investigating ambient $\mathrm{Hg}$ fluxes. ${ }^{7,17,19,25}$ Our

307 observations of peak $\mathrm{Hg}$ fluxes at soil moisture contents of 22-31\% during drying

308 suggests that emissions are likely favored at soil moisture contents slightly less than field

309 capacity (mean of $28 \%$ in this study). These patterns were particularly evident for the 0

$310 \mathrm{~cm}$ and $1 \mathrm{~cm}$ amended experiments, which showed similar timing responses to one

311 another although the magnitude of the flux was considerably less for the $1 \mathrm{~cm}$ amended

312 experiments. For the surface soil amended experiments, the maximum post-wetting $\mathrm{Hg}$

313 fluxes were up to $285 \mathrm{ng} \mathrm{m}^{-2} \mathrm{~h}^{-1}$ whereas for the $1 \mathrm{~cm}$ tracer amended experiments, the

314 maximum post-wetting $\mathrm{Hg}$ fluxes were up to $126 \mathrm{ng} \mathrm{m}^{-2} \mathrm{~h}^{-1}$. When the tracer $\mathrm{Hg}$

315 amended soil was deeper in the mesocosm (i.e. $2 \mathrm{~cm}$ and $5 \mathrm{~cm}$ ), emissions were less than

316 those observed for near-surface tracer applications, but mostly still detectable (maximum

317 flux up to $14 \mathrm{ng} \mathrm{Hg}^{199} \mathrm{~m}^{-2} \mathrm{~h}^{-1}$ at $2 \mathrm{~cm}$ and $12 \mathrm{ng} \mathrm{Hg}^{199} \mathrm{~m}^{-2} \mathrm{~h}^{-1}$ at $5 \mathrm{~cm}$; Figure $2 \mathrm{~B}, 3$ ).

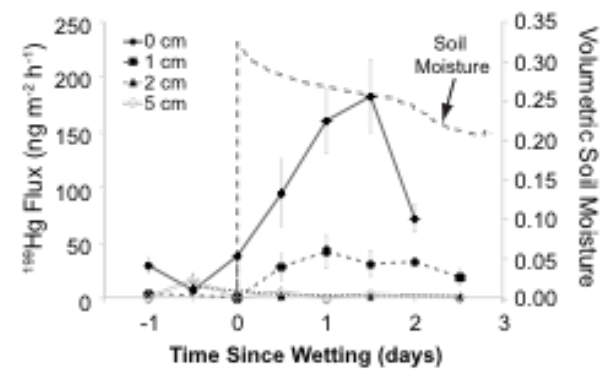

319 Figure 3: Tracer ${ }^{199} \mathrm{Hg}$ fluxes of triplicate experiments by tracer amended depth in

320 relation to median volumetric soil moisture content from all experiments. Measurements

321 corresponding to negative time since wetting represent dry soil fluxes. Flux

322 measurement values indicate means \pm standard error with measurements grouped in half-

323 day time intervals. 
325 tracer amended soil layer $(\rho=-0.862 ; p<0.0001$; Figure 4$)$, indicating that fluxes increased

326 when the tracer amended soil layer was closer to the surface. The correlation suggests

327 that $\mathrm{Hg}$ emissions approach the magnitude of our control fluxes when the $\mathrm{Hg}$ source

328 depth reaches $6.4 \mathrm{~cm}$ beneath the soil surface. The incorporation of a tracer in our

329 experiment shows that $76 \%$ of the tracer fluxes originated from the top $1 \mathrm{~cm}$ of the soil,

$33016 \%$ originated from the 1-2 cm layer, and $8 \%$ overall from soil between $2 \mathrm{~cm}$ and $6 \mathrm{~cm}$

331 depth. Transport processes in sandy soils similar to those used in the mesocosms are

332 therefore capable of acting over a somewhat broader range than previously suspected, but

333 as previously inferred are indeed dominated by processes within the first $2 \mathrm{~cm}$ of the

334 surface..$^{10,13,14}$

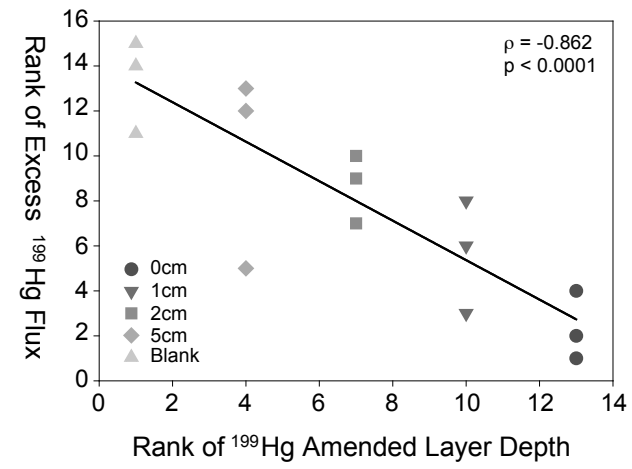

336 Figure 4: Spearman correlation between tracer $\mathrm{Hg}$ amended soil layer depth and tracer

$337 \mathrm{Hg}$ flux, under wet soil conditions.

339 another, especially for tracer $\mathrm{Hg}$ amended soils at $0 \mathrm{~cm}$ and $1 \mathrm{~cm}$ depths, temporal lags

340 were apparent and so there was not a direct correlation between \% soil moisture and $\mathrm{Hg}$

341 emissions (e.g. $0 \mathrm{~cm}: \rho=-0.2581, \mathrm{p}=0.1764)$. Any correlation between soil moisture and 
$342 \mathrm{Hg}$ emissions is likely dependent on the degree to which the soil moisture is increased.

343 For example, studies with relatively low soil moisture contents $(<20 \%)$ have shown

344 strong correlations with emissions; ${ }^{19}$ whereas studies in wetter soils such as ours do not

345 show this correlation, due to flux suppression at the highest moisture levels. ${ }^{17}$ Flux

346 suppression at saturated soil contents is thought to occur due to water filling the soil pore

347 spaces and reducing gas exchange with the atmosphere ${ }^{19,41}$. It is clear from our data and

348 others that a singular relationship between a particular soil moisture content and $\mathrm{Hg}$ flux

349 does not exist. Rather, the increase in flux is related to a particular change in soil

350 moisture (i.e., drying out), and thus potentially either to changes in soil water tension or

351 evaporation. This is somewhat in line with a hypothesis forwarded by Bahlmann et al. ${ }^{41}$

352 who suggested that maximal $\mathrm{Hg}$ fluxes are supported at a particular soil moisture content

353 but that $\mathrm{Hg}$ fluxes would decline if this optimal soil moisture were exceeded. However,

354 our findings align better with the conceptual model recently put forward by Briggs and

355 Gustin $^{17}$ that $\mathrm{Hg}$ flux is strongly controlled by the evaporative stage of soil moisture and

356 work by Gustin and Stamenkovic ${ }^{19}$ that upward transport and subsequent deposition of

$357 \mathrm{Hg}$ nearer the soil surface may occur, facilitating continued fluxes as soils dry. If $\mathrm{Hg}$

358 transport were facilitated by soil water tension at the surface during soil drying, one

359 might expect that the depth of $\mathrm{Hg}$ sources that could participate in emissions could be

360 even deeper in fine-grained soils such as silts and clays because of stronger capillary

361 forces. Alternatively, $\mathrm{Hg}$ transport facilitated by the opening of pore spaces during soil

362 drying, allowing deeper participation of evaporative losses, may be less sensitive to soil

363 properties. While the work of Briggs and Gustin ${ }^{17}$ suggests the latter, additional 
364 experimental work is needed to verify the mechanisms and thus the potential depths of

$365 \mathrm{Hg}$ sources for emission in different soil types.

366 Measurements of tracer $\mathrm{Hg}$ in soil after the moisture experiments showed that

367 there was no significant migration above or below the layer where it was placed (Figure

368 5). The relatively small and highly variable pools found in the layers immediately above

369 our 2-cm and 5-cm experiments most likely represent inadvertent mixing of layers when

370 sampling. We caution that our use of deionized water as input to the experiments differs

371 from natural rainwater, and that this may affect the dissolution and transport of

372 subsurface Hg though it is likely that a percolating soil solution would quickly gather

373 ligands from the soil matrix. Still, it is important to note that outside of the surface tracer

374 experiment, we observed no accumulation of tracer at the surface from any of the other,

375 more deeply applied tracer experiments. Therefore our results do not show that $\mathrm{Hg}$ is

376 transported from deeper in the soil profile and accumulated at the surface to fuel longer-

377 term reduction and emissions, but rather that the transport mechanism occurs over a short

378 time period and without re-oxidation of $\mathrm{Hg}^{0}$. Such findings are unique and indicate that a

379 relatively direct connection between subsurface $\mathrm{Hg}$ pools and the atmosphere can exist.
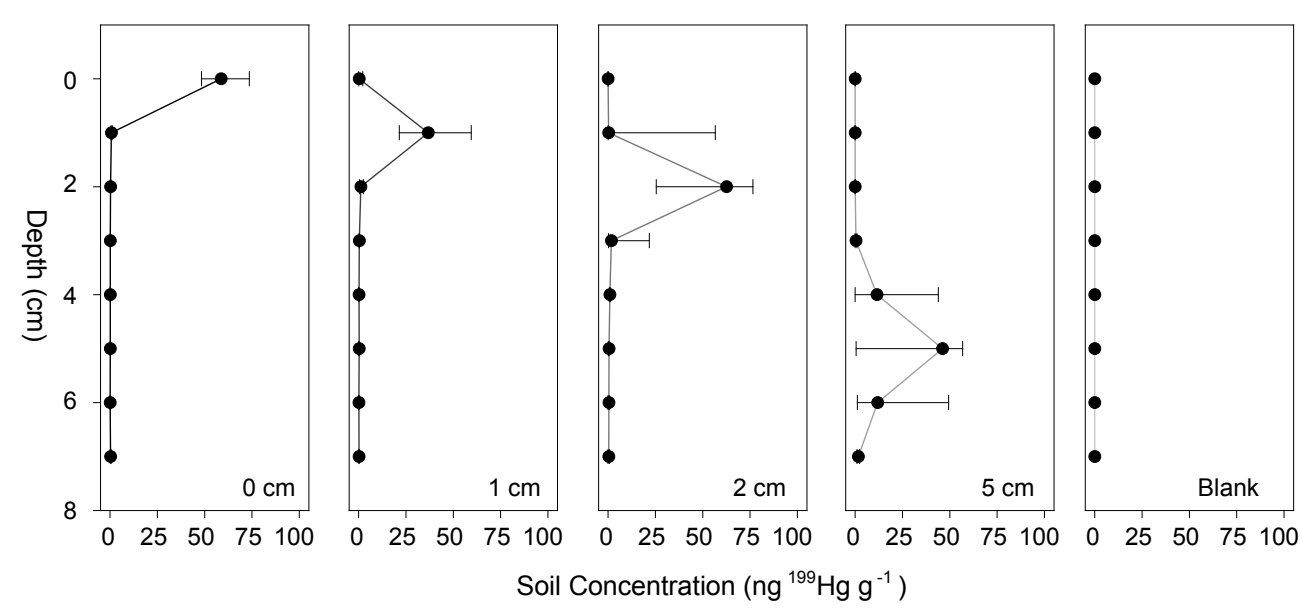
381 Figure 5: Median soil concentration of tracer ${ }^{199} \mathrm{Hg}$ after conclusion of wet flux

382 measurements, grouped by depth of the ${ }^{199} \mathrm{Hg}$ amended layer. Error bars represent range

383 of observations from triplicate experiments.

384 While this tracer experiment demonstrates that subsurface $\mathrm{Hg}$ sources $(\geq 5 \mathrm{~cm}$

385 depth) participate in surface $\mathrm{Hg}$ emissions, these fluxes are clearly dominated by nearer

386 surface sources ( $0-2 \mathrm{~cm}$ depth), especially when soils are moist. We observed that $0.4 \%$

387 of the amended tracer $\mathrm{Hg}$ at $0 \mathrm{~cm}$ was emitted from the soil over the course of the post

388 wetting flux peak which lasted $\sim 3$ days. Similar results from studies using stable isotope

389 tracers have observed $0.1-3 \%$ re-emission of tracer $\mathrm{Hg}$ over the period immediately

390 following wetting. ${ }^{25}$ There is some uncertainty as to the susceptibility of recently

391 deposited versus legacy pools of $\mathrm{Hg}$ for emission, with as much as $10 \%$ of $\mathrm{Hg}$ isotope

392 tracer re-emitted on a seasonal basis. ${ }^{42}$ While the reactivity of native pools of older $\mathrm{Hg}$

393 found at deeper depths requires further research, our findings suggest that subsurface $\mathrm{Hg}$

394 pools may not be entirely sequestered and have the potential to participate in surface

395 emissions. These results have important implications for the ability of $\mathrm{Hg}$ pollution to

396 continue to actively cycle between soil and the atmosphere long after initial deposition

397 has occurred.

399 ACKNOWLEDGEMENTS

400 Haiyong (Planck) Huang gratefully provided assistance with laboratory analysis.

401 Funding for this research was provided by a Natural Sciences and Engineering Research

402 Council Discovery Grant to CPJM. 


\section{4. References}

404 1. Poissant, L.; Casimir, A. Water-air and soil-air exchange rate of total gaseous mercury

405 measured at background sites. Atmos. Environ. 1998, 32, 883-893.

406 2. Grigal, D.F. Inputs and outputs of mercury from terrestrial watersheds: A review.

$407 \quad$ Environ. Rev. 2002, 10, 1-39.

408 3. Bahlmann, E.; Ebinghaus, R.; Ruck, W. Development and application of a laboratory

409 flux measurement system (LFMS) for the investigation of the kinetics of mercury

410 emissions from soils. J. Environ. Manage. 2006, 81, 114-125.

411 4. Gustin, M.S.; Engle, M.; Ericksen, J.; Lyman, S.; Stamenkovic, J.; Xin, M. Mercury

412 exchange between the atmosphere and low mercury containing substrates. Appl.

413 Geochem. 2006, 21, 1913-1923.

414 5. Eckley, C.S.; Gustin, M.; Lin, C.-J.; Li, X.; Miller, M.B. The influence of dynamic

415 chamber design on operating parameters on calculated surface-to-air mercury fluxes.

416 Atmos. Environ. 2010, 44, 194-203.

417 6. Eckley, C.S.; Gustin, M.; Marsik, F.; Miller, M.B. Measurement of surface mercury

418 fluxes at active industrial gold mines in Nevada (USA). Sci. Total Environ. 2011, 409,

$419 \quad 514-522$.

420 7. Lin, C.J.; Gustin, M.S.; Singhasuk, P.; Eckley, C.; Miller, M. Empirical models for

421 estimating mercury flux from soils. Environ. Sci. Technol. 2010, 44, 8522-8528.

422 8. Kim, K.H.; Lindberg, S.E.; Meyers, T.P. Micrometeorological measurements of

423 mercury-vapor fluxes over background soils in eastern Tennessee. Atmos. Environ.

$424 \quad 1995,29,267-282$. 
425 9. Zhang, H.; Lindberg, S.E.; Marsik, F.J.; Keeler, G.J. 2001. Mercury air/surface

426 exchange kinetics of background soils of the Tahquamenon river watershed in the

427 Michigan Upper Peninsula. Water Air Soil Pollut. 2001, 126, 151-169.

428 10. Gustin, M.S.; Biester, H.; Kim, C.S. Investigation of light-enhanced emission of 429 mercury from enriched substrates. Atmos. Environ. 2002, 36, 3241-3254.

430 11. Moore, C.; Carpi, A. Mechanisms of the emission of mercury from soil: Role of $431 \quad$ UV radiation. J. Geophys. Res. 2005, 110, D24302.

432 12. Hutchison, B.A.; Matt, D.R. The distribution of solar radiation within a deciduous 433 forest. Ecol. Monogr. 1977, 47, 185-207.

434 13. Carpi, A.; Lindberg, S.E. Sunlight-mediated emission of elemental mercury from 435 soil amended with municipal sewage sludge. Environ. Sci. Technol. 1997, 31, 20854362091.

437 14. Xin, M.; Gustin, M.; Johnson, D. Laboratory investigation of the potential for re438 emission of atmospherically derived Hg from soils. Environ. Sci. Technol. 2007, 41, $439 \quad 4946-4951$.

440 15. Obrist, D. Mercury distribution across 14 U.S. forests. Part II: Patterns of methyl 441 mercury concentrations and areal mass of total and methyl mercury. Environ. Sci.

442 Technol. 2012, 46, 5921-5930.

443 16. Quinones, J.L.; Carpi, A. An investigation of the kinetic processes influencing 444 mercury emissions from sand and soil samples of varying thickness. J. Environ. Qual. $445 \quad 2011,40,647-652$. 
446 17. Briggs, C.; Gustin, M.S. Building upon the conceptual model for soil mercury

447 flux: Evidence of a link between moisture evaporation and Hg evasion. Water Air Soil $448 \quad$ Pollut. 2013, 224, 1744.

449 18. Engle, M.A.; Gustin, M.S.; Zhang, H. Quantifying natural source emissions from 450 the Ivanhoe Mining District, north-central Nevada, USA. Atmos. Environ. 2001, 25 , $451 \quad 3987-3997$.

452 19. Gustin, M.S.; Stamenkovic, J. Effect of watering and soil moisture on mercury 453 emission from soils. Biogeochemistry, 2005, 76, 215-232.

454 20. Song, X.X.; Van Heyst, B. Volatilization of mercury from soils in response to 455 simulated precipitation. Atmos. Environ. 2005, 39, 7494-7505.

456 21. Lindberg, S.E.; Zhang, H.; Gustin, M.; Vette, A.; Marsik, F.; Owens, J.; Casimir, 457 A.; Ebinghaus, R.; Edwards, G.; Fitzgerald, C.; Kemp, J.; Kock, H.H.; London, J.; 458 Majewski, M.; Poissant, L.; Pilote, M.; Rasmussen, P.; Schaedlich, F.; Schneeberger, 459 D.; Sommar, J.; Turner, R.; D. Wallschlager; Z. Xiao. Increases in mercury emissions 460 from desert soils in response to rainfall and irrigation. J. Geophys. Res.-Atmos. 1999, $461 \quad 104,21879-21888$.

462 22. Wang, S.F.; Feng, X.B.; Qiu, G.L.; Wei, Z.Q.; Xiao, T.F. Mercury emission to 463 atmosphere from Lanmuchang $\mathrm{Hg}-\mathrm{Tl}$ mining area, Southwestern Guizhou, China. 464 Atmos. Environ. 2005, 39, 7459-7473.

465 23. Kocman, D.; Horvat, M. A laboratory based experimental study of mercury 466 emission from contaminated soils in the River Idrijca catchment. Atmos. Chem. Phys.

$467 \quad 2010,10,1417-1426$. 
468 24. Mazur, M.; Mitchell, C.P.J.; Eckley, C.S.; Eggert, S.L.; Kolka, R.K.; Sebestyen, 469 S.D.; Swain, E.B. Gaseous mercury fluxes from soils in response to forest harvesting 470 intensity: A field manipulation experiment. Sci. Total Environ. 2014, 496, 678-687.

471 25. Ericksen, J.A.; Gustin, M.S.; Lindberg, S.E.; Olund, S.D.; Krabbenhoft, D.P. 472 Assessing the potential for re-emission of mercury deposited in precipitation from arid 473 soils using a stable isotope. Environ. Sci. Technol. 2005, 39, 8001-8007.

474 26. Haynes, K.M.; Mitchell, C.P.J. Inter-annual and spatial variability in hillslope 475 runoff and mercury flux during spring snowmelt. J. Environ. Monitor. 2012, 14, 20834762091.

477 27. Grigal, D.F. Mercury sequestration in forests and peatlands: a review. J. Environ. 478 Qual. 2003, 32, 393-405.

479 28. Vaze, J.; Chiew, F.H.S. Study of pollutant washoff from small impervious $480 \quad$ experimental plots. Water Resour. Res. 2003, 39, 1160.

481 29. Stone, D.M.; Elioff, J.D. Soil properties and aspen development five years after 482 compaction and forest floor removal. Can. J. Soil Sci. 1998, 78, 51-58.

483 30. U.S. Environmental Protection Agency. Compendium method IO-5: Sampling and 484 analysis for vapor and particle phase mercury in ambient air utilizing cold vapor 485 atomic fluorescence spectrometry (CVAFS). Center for Environmental Research 486 Information, Office of Research and Development, Cincinnati, OH, 1999.

487 31. Hintelmann, H.; Evans, R.D. Application of stable isotopes in environmental 488 tracer studies - Measurement of monomethlymercury $\left(\mathrm{CH}_{3} \mathrm{Hg}^{+}\right)$by isotope dilution 489 ICP-MS and detection of species transformation. Fresen. J. Anal. Chem. 1997, 358, $490 \quad 378-385$. 
491 32. U.S. Environmental Protection Agency. Method 3051A: Microwave assisted acid 492 digestion of sediments, sludges, soils and oils. Office of Solid Waste; Economic, 493 Methods, and Risk Analysis Division, Washington, DC, 2007.

494 33. U.S. Environmental Protection Agency. Method 1631, Revision E: Mercury in 495 water by oxidation, purge and trap, and cold vapor atomic fluorescence spectrometry.

496 US EPA Statistics and Analytical Support Branch, Washington, DC, 2002.

497 34. RStudio. RStudio: Integrated development environment for R (Version 498 0.98.1091) [Computer software]. Boston, MA. Retrieved November 27, 2014. 499 Available from http://www.rstudio.org/

500 35. Zhang, H.; Lindberg, S.E.; Kuiken, T. Mysterious diel cycles of mercury 501 emission from soils held in the dark at constant temperature. Atmos. Environ. 2008, $502 \quad 42,5424-5433$.

503 36. Kim, K.H.; Yoon, H.O.; Jung, M.C.; Oh, J.M.; Brown, R.J.C. A simple approach 504 for measuring emission patterns of vapor phase mercury under temperature-controlled 505 condition from soil. Sci. World J. 2012, 940413.

506 37. Mauclair, C.; Layshock, J.; Carpi, A. Quantifying the effect of humic matter on 507 the emissions of mercury from artificial soil surfaces. Appl. Geochem. 2008, 23, 594$508 \quad 601$

509 38. Moore, C.W.; Castro, M.S. Investigation of factors affecting gaseous mercury $510 \quad$ concentrations in soils. Sci. Total Environ. 2012, 419, 136-143.

511 39. Schluter, K. Review: evaporation of mercury from soils. An integration and 512 synthesis of current knowledge. Environ. Geol. 2000, 39, 249-271. 
513 40. Barkay, T.; Miller, S.M.; Summers, A.O. Bacterial mercury resistance from 514 atoms to ecosystems. FEMS Microbiol. Rev. 2003, 27, 355-384.

515 41. Bahlmann, E.; Ebinghaus, R.; Ruck, W. The effect of soil moisture on the 516 emission of mercury from soils. Mater. Geoenviron. 2004, 51, 791-794.

517 42. Hintelmann, H.; Harris, R.; Heyes, A.; Hurley, J.P.; Kelly, C.A.; Krabbenhoft, 518 D.P.; Lindberg, S.; Rudd, J.W.M.; Scott, K.J.; St. Louis, V.L. Reactivity and mobility 519 of new and old mercury in a boreal forest ecosystem during the first year of the 520 METAALICUS study. Environ. Sci. Technol. 2002, 36, 5034-5040. 


\section{Figure Captions}

523 Figure 1: Diagram of the experimental apparatus. This example is for an experiment with

$524{ }^{199} \mathrm{Hg}$ amended soil at 2-cm depth.

525 Figure 2: Box plots of: A) ambient $\mathrm{Hg}$ fluxes, B) tracer $\mathrm{Hg}$ fluxes in relation to depth of

526 the enriched stable $\mathrm{Hg}$ isotope tracer amended 1-cm soil layer. Boxes correspond to range

527 between $25^{\text {th }}$ and $75^{\text {th }}$ percentiles, with medians marked. Where data available, $5^{\text {th }}$ and

$52895^{\text {th }}$ percentiles represented by whiskers. The ambient $\mathrm{Hg}$ fluxes were measured at the

529 same time as the tracer Hg fluxes; however the soil depth where the ambient flux

530 originated should not be inferred from the data. Instead, the ambient data represents the

531 variability in flux measurements that occurred through the experiment that is un-related

532 to the tracer $\mathrm{Hg}$ addition to the soil. Overall, the ambient data showed that conditions

533 were relatively stable throughout the experiment.

534 Figure 3: Tracer ${ }^{199} \mathrm{Hg}$ fluxes of triplicate experiments by tracer amended depth in

535 relation to median volumetric soil moisture content from all experiments. Measurements

536 corresponding to negative time since wetting represent dry soil fluxes. Flux

537 measurement values indicate means \pm standard error with measurements grouped in half-

538 day time intervals.

539 Figure 4: Spearman correlation between tracer $\mathrm{Hg}$ amended soil layer depth and tracer

$540 \quad \mathrm{Hg}$ flux, under wet soil conditions. 
$541 \quad$ Figure 5: Median soil concentration of tracer ${ }^{199} \mathrm{Hg}$ after conclusion of wet flux

542 measurements, grouped by depth of the ${ }^{199} \mathrm{Hg}$ amended layer. Error bars represent range

543 of observations from triplicate experiments. 